\title{
Bio-based Rigid Polyurethane Foam Prepared from Apricot Stone Shell-based Polyol for Thermal Insulation Application - Part 2: Morphological, Mechanical, and Thermal Properties
}

\author{
Muhammed Said Fidan * and Murat Ertaş
}

The procedure for the liquefaction of apricot stone shells was reported in Part 1. Part 2 of this work determines the morphological, mechanical, and thermal properties of the bio-based rigid polyurethane foam composites (RPUFc). In this study, the thermal conductivity, compressive strength, compressive modulus, thermogravimetric analysis, flammability tests (horizontal burning and limited oxygen index (LOI)) in the flame retardants), and scanning electron microscope (SEM) (cell diameter in the SEM) tests of the RPUFc were performed and compared with control samples. The results showed the thermal conductivity (0.0342 to 0.0362 $\mathrm{mW} / \mathrm{mK}$ ), compressive strength (10.5 to $14.9 \mathrm{kPa}$ ), compressive modulus (179.9 to $180.3 \mathrm{kPa}$ ), decomposition and residue in the thermogravimetric analysis (230 to $491{ }^{\circ} \mathrm{C}, 15.31$ to $21.61 \%$ ), UL-94 and LOI in the flame retardants (539.5 to $591.1 \mathrm{~mm} / \mathrm{min}, 17.8$ to $18.5 \%$ ), and cell diameter in the SEM (50.6 to $347.5 \mu \mathrm{m})$ of RPUFc attained from liquefied biomass. The results were similar to those of foams obtained from industrial RPUFs, and demonstrated that bio-based RPUFc obtained from liquefied apricot stone shells could be used as a reinforcement filler in the preparation of RPUFs, specifically in construction and insulation materials. Moreover, liquefied apricot stone shell products have potential to be fabricated into rigid polyurethane foam composites.

Keywords: Thermal properties; Rigid polyurethane foam; Apricot stone shell; Morphological properties; Characterization

Contact information: Department of Forest Industry Engineering, Faculty of Forestry, Bursa Technical University, 16310, Bursa, Turkey; *Corresponding author: said.fidan@btu.edu.tr

\section{INTRODUCTION}

The rigid polyurethane foams (RPUFs) industry is still intensely petroleumdependent because its two major feedstocks, isocyanates and polyols, are petroleum derived. Nevertheless, due to uncertain prices of petroleum in the future, and the need to move towards more environmentally friendly feedstocks, many recent attempts have concentrated on replacing all or part of the conventional petroleum-based polyols by alternatives attained from renewable resources (Gama et al. 2015a).

Rigid polyurethane foams are a class of lightweight porous materials of tremendous interest due to their potential application and specific properties in various areas. They can be categorized as rigid, semi-rigid, and flexible foams, relying on the mechanical characteristics, density, and cell morphology. Among the foamed polymers used commercially, RPUFs have the lowest thermal conductivity (Gama et al. 2015a). 
Various processes that produce non-petroleum derived polyols and many nonpetroleum resources are used in polyurethane foam fabrication. Processes include the acid liquefaction of various biomass residuals, and the modification of vegetable oils, such as oxypropylation (Aniceto et al. 2012). Additionally, various sequencing strategies are used to fabricate renewable polyols for the polyurethane foam industry (Gama et al. 2015a).

The acid liquefaction of biomass resources to fabricate bio-based rigid polyurethane foams can include bamboo (Xie et al. 2014), coffee grounds (Gama et al. 2015a), cork (Gama et al. 2015b; Esteves et al. 2017), corn stalk (Yan et al. 2008), corn bran (Lee et al. 2000), cotton burrs (Fidan and Ertaş 2020a), eucalyptus, pine woods (Ertaş et al. 2014), lignin (Xue et al. 2015; Mahmood et al. 2016), pine bark and peanut shell (Zhang et al. 2020), soybean straw (Hu et al. 2012), sugar-cane bagasse (Hakim et al. 2011; Xie et al. 2015), waste paper (Lee et al. 2002), wheat straw (Chen and Lu 2009), wood bark (Zhao et al. 2012), wood powder (Zhang et al. 2013), and yaupon holly (Huang et al. 2017a).

The construction industry can play a significant role in sustainable development. The use of environment-friendly materials in modern buildings not only can considerably decrease construction waste, but it also avoids excessive use of natural resources. When considering the industry's position, the utilization of biomass resources, particularly crop residuals, is an effective way to protect the environment and to save energy in the building industry. Utilization of biomass can greatly decrease $\mathrm{CO}_{2}$ emissions (Zhang et al. 2020).

In the construction of buildings, RPUFs are a polymer material widely used for sound absorption and thermal insulation due to their thermal stability (Czuprynski et al. 2010; Vitkauskiene et al. 2011; Luo et al. 2016; Sung et al. 2016; Tiuc et al. 2016; Zhang et al. 2020). They have easy combustion, low density, and a large surface area (Modesti et al. 2001; Tang et al. 2002; Levchik and Weill 2004; Chen et al. 2019). They must be properly modified because of their low fire retardant capacity. As such, the preparation of RPUFs with increased fire resistance has rendered them flame retardant (Czech-Polak et al. 2016). In regard to bio-based RPUFs, bio-based polyols, which could be fabricated from plant fibers (Zhang et al. 2013; Xie et al. 2015; Zhang et al. 2020) and vegetable oils (Kuranska and Prociak 2016), are commonly served as raw materials owing to the existence of abundant hydroxyl groups or double bonds in these polyols (Zhang et al. 2020).

The raw material used to produce renewable polyols in this study was apricot stone shell. It is an agricultural product of high economic and ecological benefit. The utilization of biomass, especially crop wastes, is an effective way to save energy and protect the environment in the building industry. Therefore, the utilization of biomass resources will substantially decrease excessive $\mathrm{CO}_{2}$ emissions. The aim of this study was to obtain the following properties of RPUFc: compressive strength, compressive modulus, thermal conductivity, as well as conduct thermogravimetric analysis, flammability tests and scanning electron microscopy analysis.

\section{EXPERIMENTAL}

\section{Materials}

The apricot stone shells were collected at Kahramanmaras Agricultural Research Institute, Kahramanmaras, Turkey. They were collected in $37^{\circ} 32^{\prime} 08 \mathrm{~K}, 37^{\circ} 32^{\prime} 08 \mathrm{D}$ and 467 altitude at local plantations. 
The procedure for the liquefaction of apricot stone shell was reported in Part 1. In this article, the apricot stone shells, having a particle size of $125 \mu \mathrm{m}$, were liquefied with a PEG-400 (polyethylene glycol-400) and glycerin mixture in the presence of sulfuric acid catalyst at 140 to $160{ }^{\circ} \mathrm{C}$ for $120 \mathrm{~min}$. The rigid polyurethane-type foam composites from the reaction were successfully prepared with different chemical materials. The results demonstrated that biobased polyurethane-type foam composites were successfully produced from the liquefied apricot stone shell. The FTIR spectra of liquefaction products confirmed the successful liquefaction of products and that they are sources of hydroxyl groups. The liquefaction yield (81.6 to $96.7 \%$ ), hydroxyl number (133.5 to $204.8 \mathrm{mg} \mathrm{KOH}$ per g), the highest elemental analysis amount (C, H, N, S, O) $(62.08,6.32,6.12,0.13$, and $25.35 \%$ ), and density ( 0.0280 to $0.0482 \mathrm{~g}$ per $\mathrm{cm}^{3}$ ) of the rigid polyurethane foam composites were comparable to foams made from commercial RPUF composites (Fidan and Ertaş 2020b).

In part 2 of this work the morphological, mechanical, and thermal properties of the bio-based rigid polyurethane foam composites (RPUFc) were determined.

\section{Methods}

Characterization tests were performed on four types of foam (Foam Code: RPUFc75, RPUFc-100, RPUFc-125, RPUFc-150) according to the different rate of polymeric diphenylmethane diisocyanate (pMDI 75-100-125-150) and synthetic foam (RPUFc).

\section{Characterization of RPUFC}

A BT604 universal mechanical test analyzer (Testform, Bursa, Turkey) was used to measure the compressive properties of the RPUFc. Samples $\left(30 \times 30 \times 30 \mathrm{~mm}^{3}\right)$ were placed between the two parallel plates and compressed at $10 \mathrm{~mm} / \mathrm{min}$. Six replicates were determined for each group.

The compressive modulus was calculated by the slope of the tangent of the linear part in the stress-strain profile according to the method defined in former studies (Huang et al. 2017a). The compressive modulus was determined according to ASTM D1621-10 (2010). The compressive modulus was obtained from the stress-strain curve at a deformation of $10 \%$. Six replicates were determined for each sample.

The thermal conductivity of RPUFc was measured via a FOX 314-95ET (Laser Corporation, New Castle, USA). A 10-min read time was used to minimize the contact resistance errors. Thermal conductivity was performed according to ASTMD C518 (2017). Ten replicates were carried out for each group and the average was reported.

The thermogravimetric analyses (TGA/DTG) of all RPUFc and the raw material were determined with a thermal analyzer STA 7200 (Hitachi, Japan) to simultaneously obtain thermogravimetric data. TG/DTG was used to measure the thermal degradation of RPUFc. Specimen weight was between 5 and $10 \mathrm{mg}$. Each sample was conducted at $30{ }^{\circ} \mathrm{C}$ to $800{ }^{\circ} \mathrm{C}$ with a constant heating rate of $10{ }^{\circ} \mathrm{C} / \mathrm{min}$ under a flow rate of $200 \mathrm{~mL} / \mathrm{min}$ of nitrogen atmosphere.

Horizontal burning (UL-94) tests were conducted via the UL-94 test in regard to ASTM D635-14 (2014). The RPUFc was cut into five pieces with dimensions of $125 \times 10$ $\times 13 \mathrm{~mm}^{3}$. The burning rate was determined based on Eq. 1,

$$
V=(60 \times L) / t
$$

where $V$ is the burning rate $(\mathrm{mm} / \mathrm{min}), L$ is the burned length $(\mathrm{mm})$, and $t$ is time (s). 
The LOI tests were performed using an LOI instrument according to ASTM D286397 (2019). Samples were prepared in dimensions of $100 \times 10 \times 10 \mathrm{~mm}^{3}$. The LOI measurements for each sample were repeated five times.

Scanning electron microscopy (SEM) (Gemini 300; Carl Zeiss, Oberkochen, Germany) was used to examine the morphology of the RPUFc. Prior to analysis, the specimens were coated in gold using an EM ACE600 (Leica; Carl Zeiss, Oberkochen, Germany). Images of the cross-sections of RPUFc were demonstrated. The mean cell diameter was determined from 50 measurements.

The data gathered as a result of the tests performed were recorded in Microsoft Excel (Version 2016, Redmond, WA, USA). The arithmetic averages, standard deviations, and coefficient of variation were calculated for each test and shown in related charts. Afterwards, the statistical analysis of the obtained findings was conducted. The variance analyses of findings were performed according to the Duncan test by using the SAS statistical program (SAS Institute Inc., Version 6.0, Cary, NC, USA).

The results of compressive strength and modulus samples were used to manage an analysis of variance employing a randomized block factorial experimental design using the SAS statistical program. The mean values were compared using the Duncan test. Ultimately, multiple correlation analysis was performed in an attempt to analyze the relationship between groups.

\section{RESULTS AND DISCUSSION}

\section{SEM Analysis}

As presented in Fig. 1, the RPUFc based on the pMDI ratio had a comparatively small cell diameter. The cell diameters were measured on the surface of the RPUFc with different pMDI ratios derived from liquefied apricot stone shell. The values are listed in Table 1.

The cell diameters of foams with RPUFc-75, RPUFc-100, RPUFc-125, RPUFc150, and the control (RPUFc) based on the pMDI ratio were 115.4, 128.4, 131.6, 162.4, and $207.0 \mu \mathrm{m}$, respectively (Table 1).

Table 1. Cell Diameters of the RPUFc

\begin{tabular}{|c|c|}
\hline Foam Code & Cell Diameter $(\mu \mathrm{m})$ \\
\hline RPUFc-75 & 115.38 \\
\hline RPUFc-100 & 128.39 \\
\hline RPUFc-125 & 131.59 \\
\hline RPUFc-150 & 162.43 \\
\hline RPUFc & 207.02 \\
\hline
\end{tabular}

The cell diameters ranged between 50.6 and $238.7 \mu \mathrm{m}$ in RPUFc-75, between 51.4 and $301.3 \mu \mathrm{m}$ in RPUFc-100, between 63.4 and $309.2 \mu \mathrm{m}$ in RPUFc-125, between 67.4 and $316.5 \mu \mathrm{m}$ in RPUFc-150, and between 77.1 and $347.5 \mu \mathrm{m}$ in RPUFc. The increase in the pMDI increased the cell diameter. When higher numbers of pMDI were used, the ensuing foams had more cells with larger diameters (Fig. 1). 

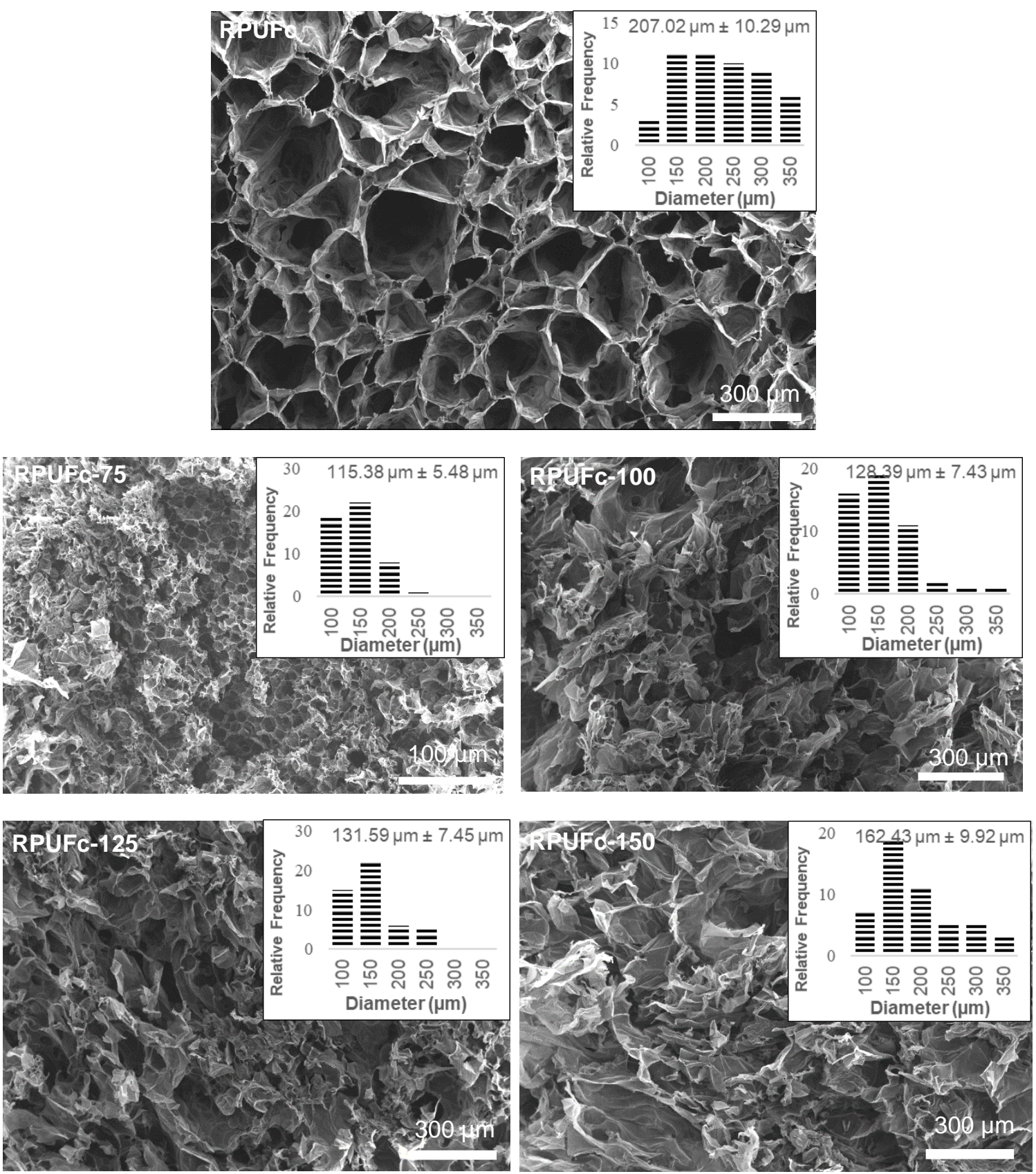

Fig. 1. The SEM images of the RPUFc (Magnification: $\times 30$, Accelerating voltage: $15 \mathrm{kv}$ )

As reported in the literature, the cells are usually closed. Because the pore size and cell structure of RPUF are closely connected to their mechanical properties and thermal conductivity, it is necessary to characterize the microstructure of biofoams (Gama et al. 2015a). These RPUF had closed cells with a polyhedral structure, differing from the open cellular structure generally observed for flexible polyurethane foams. The use of $100 \%$ biobased polyol for RPUF production afforded foams that were dominated by smaller pore size and greater homogeneity (Esteves et al. 2017). Akdogan et al. (2019) speculated that small changes in the number of closed cells, similar to those in their own work, did not have an important effect on compressive strength and thermal conductivity. It was found that the foam cells were more regular and smooth with an increased isocyanate index from 
105 to 150 . At an isocyanate index between 105 and 135, the pore diameter gradually grew from $161.5 \mu \mathrm{m}$ to $242.1 \mu \mathrm{m}$. Conversely, with a further surge in the isocyanate index to 150 , pore diameter dropped to $223.5 \mu \mathrm{m}$. It is conceivable that the increase of pore diameter contributed to the increased amount of $\mathrm{CO}_{2}$ that correlated with an increasing isocyanate index. Nevertheless, the diminishing pore size at PU150 was probably due to increasing cell wall elasticity, which could attribute to restricting the $\mathrm{CO}_{2}$ blowing and expanding, resulting in a smaller pore diameter (Huang et al. 2017a).

\section{Compressive Strength and Modulus}

The mean values and the groups resulting from the Duncan analysis of the compressive strength and modulus of RPUFc are listed in Table 2. The differences in the compressive strength and modulus were significant to a level of $1 \%$ for the effects of RPUFc-75, RPUFc-100, RPUFc-125, RPUFc-150, and RPUFc.

Table 2. Mean Values and Groups Resulting from the Duncan Analysis of the Compressive Strength and Modulus of the RPUFc

\begin{tabular}{|c|c|c|}
\hline Foam Code & Compressive Strength $(\mathrm{kPa})$ & Compressive Modulus $(\mathrm{kPa})$ \\
\hline \multirow{2}{*}{ RPUFc-75 } & $10.51^{\mathrm{c}}$ & $179.907^{\mathrm{a}}$ \\
& $2.87^{\mathrm{a}}$ & 0.93 \\
\hline \multirow{2}{*}{ RPUFc-100 } & $11.44^{\mathrm{c}}$ & $179.986^{\mathrm{a}}$ \\
& 3.24 & 0.02 \\
\hline \multirow{2}{*}{ RPUFc-125 } & $11.71^{\mathrm{bc}}$ & $180.147^{\mathrm{a}}$ \\
& 2.33 & 0.17 \\
\hline \multirow{2}{*}{ RPUFc-150 } & $14.92^{\mathrm{ab}}$ & $180.123^{\mathrm{a}}$ \\
& 0.40 & 0.09 \\
\hline \multirow{2}{*}{ RPUFc } & $15.90^{\mathrm{a}}$ & $180.260^{\mathrm{a}}$ \\
\hline
\end{tabular}

${ }^{*}$ Groups with same letters in a column demonstrate that there is no statistical difference $(\mathrm{P}<$ $0.05)$ between the samples in regard to Duncan's multiply range test; **the values in italics are standard deviation

As shown in Table 2, by increasing the polymeric diphenylmethane diisocyanate (pMDI) content from $75 \%$ to $150 \%$, the compressive strength increased from 10.5 to 14.9 $\mathrm{kPa}$, and the compressive modulus ranged from 179.9 to $180.3 \mathrm{kPa}$, respectively. The impact of the pMDI amount on mechanical properties of the RPUFc was similar to that on density. The amount of compressive strengths and modulus of RPUFc-75, RPUFc-100, RPUFc-125, and RPUFc-150 was lower than commercial foams.

The range of compression stress at $10 \%$ deformation values reported for the PUFs obtained from liquefied cork was determined. It ranged from 7.7 to $34.6 \mathrm{kPa}$, and the modulus of elasticity (MOE) ranged from 183 to $475 \mathrm{kPa}$ (Gama et al. 2015a). Furthermore, the PUFs obtained from liquefied corn bran were reported to have a compressive strength at $10 \%$ strain of $76 \mathrm{kPa}$, and a compressive MOE of $140 \mathrm{kPa}$ (Lee et al. 2000; Esteves et al. 2017). The compressive strength and modulus of RPUFc produced in this work was similar to those of liquefied cork and corn bran-derived PU foam.

Moreover, due to the increase of the extent of bagasse liquefaction, the morphological features of the residue had a higher surface area and were more homogeneous. This resulted in much better adhesion between the bagasse residual and polyurethane (PU). Thus, better the compressive strength (CS) could be obtained. Additionally, it should be noted that at a fixed rate of isocyanate with the amount of weight 
percentage of bagasse residue, unreacted ingredients during liquefaction could not ensure influential strength of the RPUFc. The higher the bagasse residual amount, however poor the mechanical properties, the lower the economic price for the RPUFc. Hence, the balance point between the mechanical properties and economic price should be reached using a practical application (Xie et al. 2015).

\section{Thermal Conductivity}

Thermal conductivity of RPUF is a parameter that is fundamental to indicating thermal insulation properties. This characteristic of an RPUF depends on various factors, such as the mean density, cell size, cell orientation, thermal conductivity of the blowing agent in the cells, and closed-cell content of RPUF. As shown in Fig. 2, the thermal conductivity value of RPUFc was found to vary from 0.0342 to $0.0362 \mathrm{~mW} / \mathrm{mK}$, with the growth of pMDI from 75 to 150 , and the minimum value $(0.0342 \mathrm{~mW} / \mathrm{mK})$ was obtained from RPUFc-150. It was demonstrated that the thermal conductivity values of the RPUFc made with RPUF-125 and RPUFc-150 were lower than that of RPUFc, contrary to RPUF75 and RPUFc-100. It was clearly apparent that the presence of pMDI in the foam matrix caused an increase in the thermal conductivity and mean cell size values.

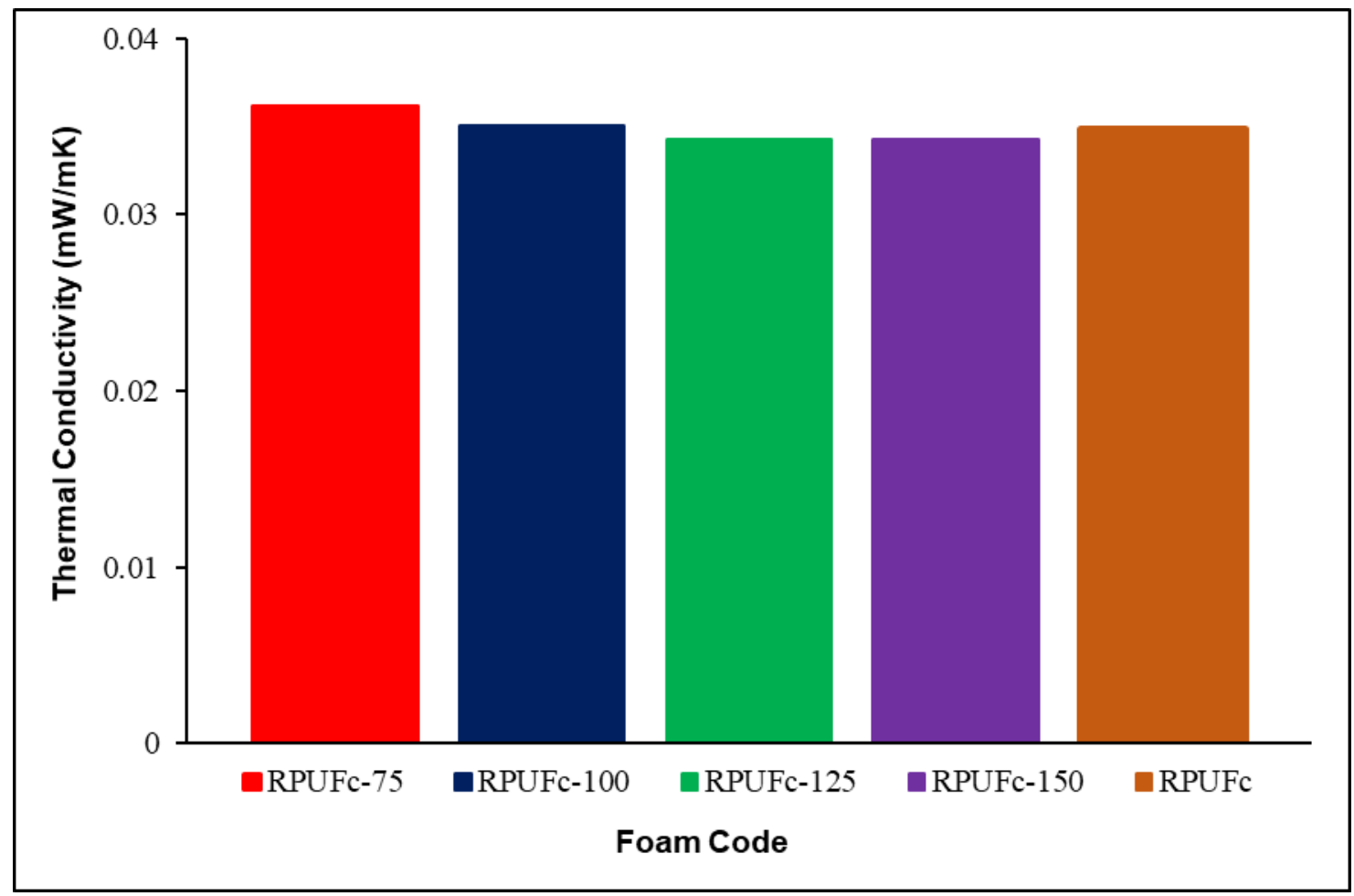

Fig. 2. The thermal conductivity of the RPUFc

It was demonstrated that the thermal conductivity value of biofoams gradually increased from 0.035 to $0.037 \mathrm{~mW} / \mathrm{mK}$ simultaneously with an increasing isocyanate index from 105 to 135 (Huang et al. 2017a). It should be noted that biofoams were satisfactory for use as insulation foam with thermal conductivity values between 0.0233 and 0.0505 $\mathrm{mW} / \mathrm{mK}$ (Gama et al. 2015a; Mahmood et al. 2016). The thermal conductivity numbers were akin to those of corn-stover-derived foam ranging from 0.032 to $0.039 \mathrm{~mW} / \mathrm{mK}$ (Hu and $\mathrm{Li}$ 2014). 
The results were ascribed to the variation of foam density. Generally, thermal conductivity is conversely proportional to the density of the PU foam, presumably due to the lower radiant heat transfer ratio through the gases trapped in small cells (Huang et al. 2017a). Thermal conductivity is the key thermal property that governs insulation applications of RPUFc. It is closely associated with cell morphology (the rate that closed cells open), cell orientation, and foam density (Huang et al. 2017a). There is a powerful relation between the thermal conductivity and mean cell diameter, namely, the smaller the mean cell diameter, the greater reduction in the thermal conductivity (Akdogan et al. 2019).

Low thermal conductivity derives from high closed-cell contents and small average cell size (Mahmood et al. 2016). The low thermal conductivity values attained for the coffee grounds derived RPUFs make them good candidates for use in thermal insulation equipment with potential applications in upholstery, refrigerator trucks, and buildings (Gama et al. 2015a).

\section{Thermogravimetric Analysis}

Figures 3 and 4 show the thermal degradation behaviors (TGA and DTG) of the RPUFc from liquefied apricot stone shell under nitrogen atmosphere. Also, Table 3 summarizes the thermal degradation of the of RPUFc from liquefied apricot stone shell under nitrogen environment.

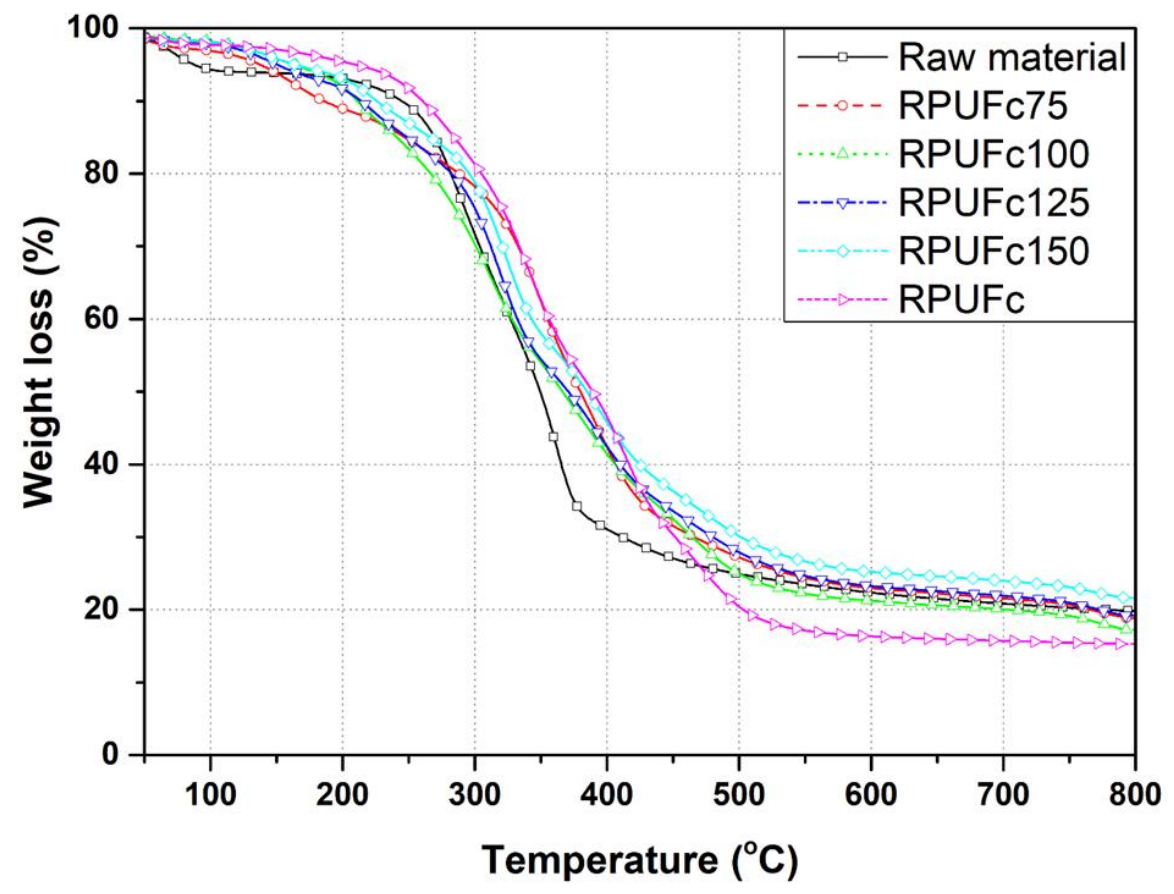

Fig. 3. The TGA curve of the RPUFc under nitrogen atmospehere

The $T_{\text {onset }}$ refers to the degradation temperature at $5 \%$ the weight loss, and $T_{\max }$ also corresponds to temperature of maximum rate of degradation.

As shown in Figures 3 and 4, all RPUFc from liquefied apricot stone showed similar TGA and DTG curves and shapes, suggesting smilar thermal degradation behaviours. The weight loss up to about $165{ }^{\circ} \mathrm{C}$ was considered to result from the release of thermally unstable diethylene glycol and the evaporation of the moisture content (Table 3). The onset 
degradation temperatures $\left(T_{\text {onset }}\right)$ of the RPUFc from liquefied apricot stone was in the range of $230.0^{\circ} \mathrm{C}$ to $282.6^{\circ} \mathrm{C}$, which was slightly than higher that of the synthetic foam. Moreover, the onset degradation and the maximum degradation tempratures of the RPUFc75 was higher than those of the synthetic foam and other biofoams, which attributed to the substitution of petroleum-based polyol with bio-based polyol from liquefaction. This improved the thermal stability of rigid PU foam due to the enhancement of the urethane linkage density of the bio-based polyol with multi hydroxyl groups (C5 and C5 sugars) (Huang et al. 2018). On the other hand, the thermal stability of the RPUFc from liquefied apricot stone slightly decreased with the increase of the pMDI (polymeric methylene diphenyl diisocyanete) rate because of the presence of thermally unstable pMDI.

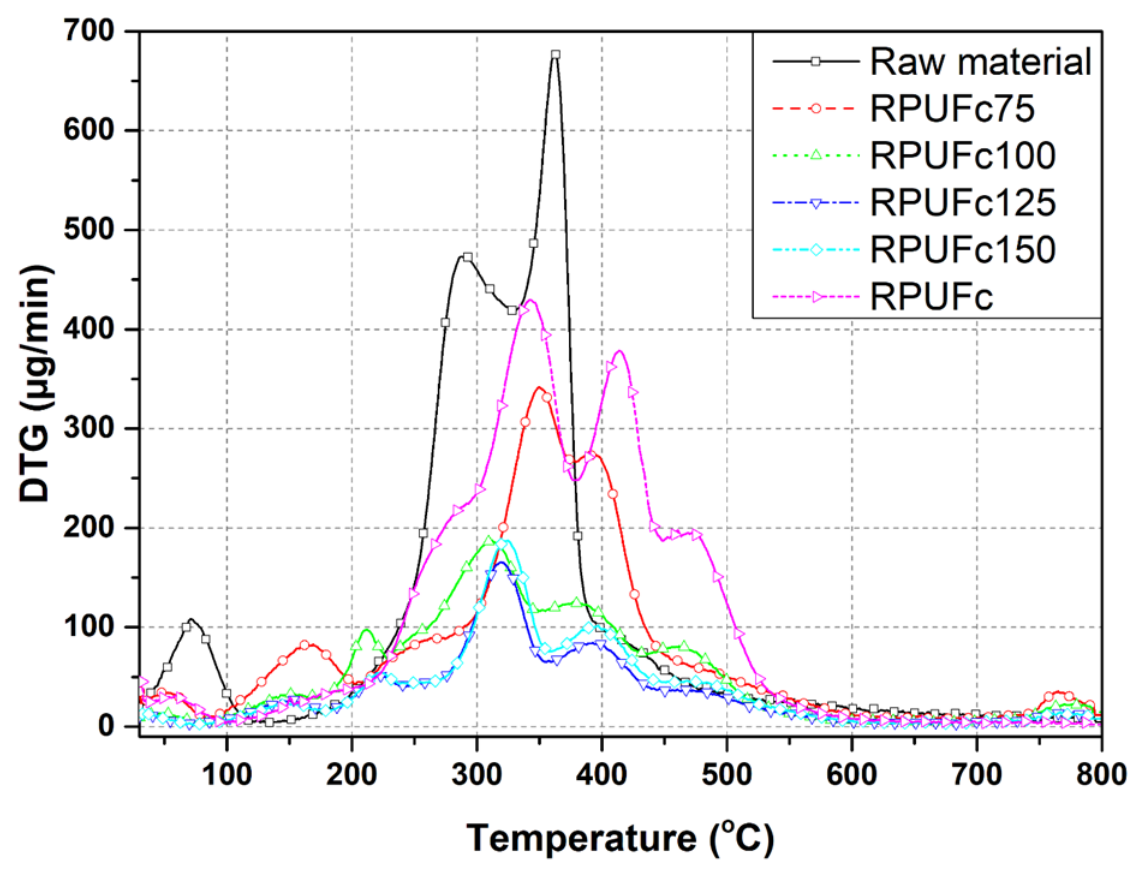

Fig. 4. The DTG curve of the RPUFc under nitrogen atmosphere

The first degradation stage between $312{ }^{\circ} \mathrm{C}$ and $349{ }^{\circ} \mathrm{C}$, could be attributed to the unstable urethane groups and partially to the degradation of diethylene glycol (Hablot et al. 2008; Huang et al. 2017a; Akdogan et al. 2019). The second stage of the important weight loss was at roughly $390{ }^{\circ} \mathrm{C}$, which could be assigned to the degradations of polyol and liquefied wood components (Zhao et al. 2012; Hu and Li 2014; Huang et al. 2017a; Janković et al. 2019; Ššstarić et al. 2020). Furthermore, due to the presence of liquefied waste in the samples, the degradation of bagasse constitutions (i.e., cellulose and hemicellulose) occurred in this temperature range (Xie et al. 2015). Eventually, the third stage centered at nearly $480{ }^{\circ} \mathrm{C}$ was ascribed to the degradation of lignin and other more sturdy compenents (Huang et al. 2017a; Ertaş et al. 2014). Furthermore, this stage also corresponded to the degradation of pMDI. The thermal degradation and stability behavior of all RPUFc from liquefied apricot stone shells were similar to those of sugarcane bagasse, yaupon holly, apricot kernel shells and apricot shells-derived PU foam (Xie et al. 2015; Huang et al. 2017a; Janković et al. 2019; Šoštarić et al. 2020). 
Table 3. TGA and DTG Data of the Raw Material and the RPUFc Under Nitrogen Atmosphere

\begin{tabular}{|c|c|c|c|c|c|}
\hline \multirow{2}{*}{ Foam Code } & \multirow{2}{*}{$\begin{array}{c}T_{\text {onset }} \\
\left({ }^{\circ} \mathrm{C}\right)\end{array}$} & \multicolumn{3}{|c|}{$T_{\max }\left({ }^{\circ} \mathrm{C}\right)$} & \multirow{2}{*}{$\begin{array}{c}\text { Residue at } \\
800{ }^{\circ} \mathrm{C}(\%)\end{array}$} \\
\cline { 3 - 5 } & & Stage 1 & Stage 2 & Stage 3 & \\
\hline Raw material & 273.3 & 362.4 & 420.3 & - & 19.85 \\
\hline RPUFc-75 & 282.6 & 349.2 & 399.1 & 491.0 & 18.86 \\
\hline RPUFc-100 & 230.0 & 312.1 & 377.9 & 459.9 & 17.23 \\
\hline RPUFc-125 & 257.6 & 319.2 & 391.9 & 476.7 & 19.22 \\
\hline RPUFc-150 & 263.7 & 324.6 & 393.6 & 477.6 & 21.61 \\
\hline RPUFc & 267.7 & 342.3 & 396.5 & 470.5 & 15.31 \\
\hline
\end{tabular}

Tonset: temperature at $5 \%$ the weight loss; $T_{\text {max: }}$ : temperature of maximum rate of degradation.

The residue yields of the RPUFc from liquefied apricot stone were higher than that of the synthetic foam, which was due to the cross-linkage cellular structure and the introduction of ash components from apricot stone (Huang et al. 2017b). Similar tendency has been reported in the literature (Ertaş et al. 2014; Huang et al. 2018).

Flammability Tests (UL-94 and LOI)

Figure 5 shows the effect of the RPUFc on the ratio of flame retardants using the vertical burning test (UL-94) and LOI.

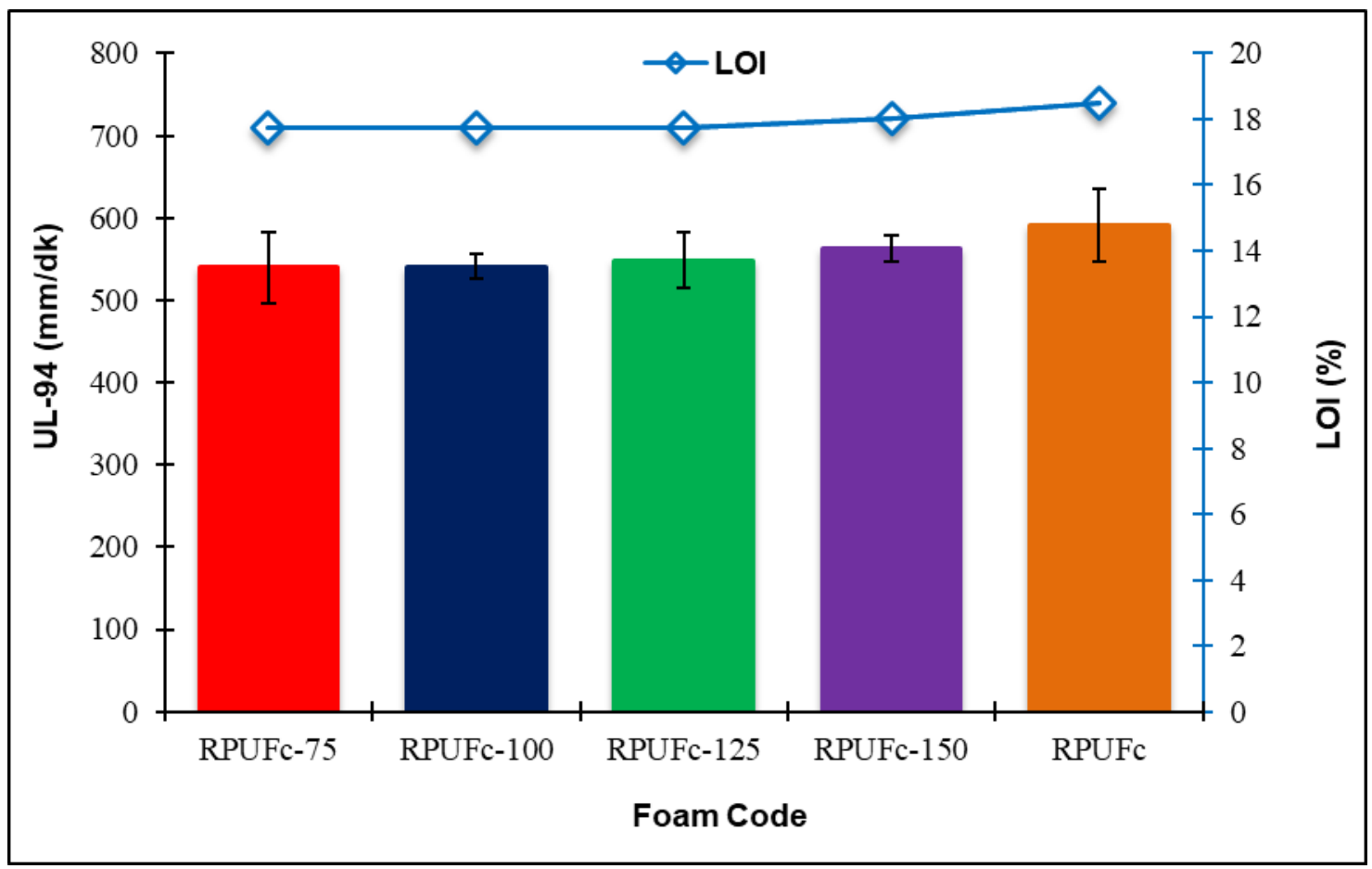

Fig. 5. The UL-94 and LOI properties of the RPUFC

As shown in Fig. 5, the flame spread rate demonstrated a rise with the increase in the amount of pMDI. The values UL-94 V were determined for pMDI-75, pMDI-100, pMDI-125, pMDI-150, and the control (RPUFc), which respectively increased to 539.5, $540.9,548.3,562.3$, and $591.1 \mathrm{~mm} / \mathrm{min}$. The foams of RPUFc-75, RPUFc-100, RPUFc- 
125, RPUFc-150, and the control (RPUFc) did not catch fire owing to the higher loading level of fire resistance. This statement was also confirmed by the results obtained during the UL-94 V test.

The LOI is a measure of the percent of oxygen. Air involves roughly $21 \%$ oxygen, and, hence, any equipment with a LOI value of less than $21 \%$ will presumably support burning in open air (Akdogan et al. 2019). As a result, the lower the flammability value, the higher the LOI. While the LOI of RPUFc was determined as $18.5 \%$, this value for RPUFc-75, RPUFc-100, RPUFc-125, and RPUFc-150 rose to 17.8, 17.8, 17.8, and 18\%, respectively. At the same time, there were no significant differences at the time the flame went out (Czech-Polak et al. 2016).

The addition of flame retardants to RPUF shifted the apparent density only relatively, but had important effects on the fire resistance. The values of LOI for prepared compositions containing flame retardants were higher than $28 \%$, allowing them to qualify as flame resistant materials (Czech-Polak et al. 2016).

\section{CONCLUSIONS}

1. The SEM micrographs of RPUFc with different levels of pMDI demonstrated that the cellular structure depends on the characteristics of the polyol used.

2. The compressive strength, and compressive modulus of the resulting RPUFc were 14.9 $\mathrm{kPa}$, and $180.1 \mathrm{kPa}$, respectively. In the mechanical properties, the RPUFc obtained with increased pMDI content was decreased as compared to control samples. In the mechanical properties, the RPUFc obtained with increased pMDI content was decreased as compared to control samples. The compressive strength and modulus values of almost all the obtained composites were lower than that of the RPUF.

3. The thermal conductivity of the resulting RPUFc was $0.0342 \mathrm{~mW} / \mathrm{mK}$. The thermal conductivities of the obtained rigid polyurethane foam composites were lower than that of the RPUF.

4. The thermal stability of the RPUFc-75 was greater than that of synthetic foam, indicating that the substitution of petroleum-based polyol with liquefaction bio-based polyol had a positive influence on the thermal stability of rigid PU foams. However, the thermal stability of the RPUFc from liquefied apricot stone slightly decreased with the increase of the pMDI loading. The thermal conductivity and thermal stability of the RPUFc obtained were within the values registered for other RPUFs derived from renewable resources, making them suitable for thermal insulation.

5. The values for UL-94 and LOI low-density RPUFc were $562.3 \mathrm{~mm} / \mathrm{min}$ and $17.8 \%$, respectively. Moreover, the cell diameter of the resulting low-density RPUFc-150 was $162.4 \mu \mathrm{m}$. The flame spread rates for RPUFc obtained with an increase in the pMDI ratio described a reduction in comparison with the RPUFs.

6. The morphological, mechanical, and thermal property characterization results demonstrate that the foam properties depended on the percentage of the physical blowing agent and the percentage of bio-contents of the apricot stone shell-based polyols. 
7. When considering the industry's position, the utilization of biomass resources, especially crop residuals, is an effective way to protect the environment and to conserve energy in the building industry. The utilization of biomass will significantly reduce $\mathrm{CO}_{2}$ emissions. Various processes that produce non-petroleum derived polyols and many non-petroleum resources are used in polyurethane foam production. For these reasons, as a consequence of the present study, the RPUFc-150 obtained from liquefied apricot stone shells could be used as a reinforcement filler in the preparation of RPUFc. It is noteworthy that this RPUFc could be used as construction and insulation material.

\section{ACKNOWLEDGEMENTS}

The authors thank the Department of Forest Industry Engineering Laboratory and Central Research Laboratory at the University of Bursa Technical University, Bursa, Turkey.

\section{REFERENCES CITED}

Akdogan, E., Erdem, M., Üreyen, M. E., and Kaya, M. (2019). "Rigid polyurethane foams with halogen-free flame retardants: Thermal insulation, mechanical, and flame retardant properties," Journal of Applied Polymer Science 137(1), Article ID 47611. DOI: 10.1002/app.47611

Aniceto, J. P. S., Portugal, I., and Silva, C. M. (2012). "Biomass-based polyols through oxypropylation reaction," ChemSusChem 5(8), 1358-1368. DOI: $10.1002 /$ cssc. 201200032

ASTMD C518 (2017). "Standard test method for steady-state thermal transmission properties by means of the heat flow meter apparatus," ASTM International, West Conshohocken, PA, USA.

ASTM D635-14 (2014). "Standard test method for rate of burning and/or extent and time of burning of plastics in a horizontal position," ASTM International, West Conshohocken, PA, USA.

ASTM D1621-10 (2010). "Standard test method for compressive properties of rigid cellular plastics," ASTM International, West Conshohocken, PA, USA.

ASTM D2863-97 (2019). "Standard test method for measuring the minimum oxygen concentration to support candle-like combustion of plastics (oxygen index)," ASTM International, West Conshohocken, PA, USA.

Chen, F., and Lu, Z. (2009). "Liquefaction of wheat straw and preparation of rigid polyurethane foam from the liquefaction products," Journal of Applied Polymer Science 111(1), 508-516. DOI: 10.1002/app.29107

Chen, X., Li, J., and Gao, M. (2019). "Thermal degradation and flame retardant mechanism of the rigid polyurethane foam including functionalized graphene oxide," Polymers 11(1), Article number 78. DOI: 10.3390/polym11010078

Czech-Polak, J., Przybyszewski, B., Heneczkowski, M., Czulak, A., and Gude, M. (2016). "Effect of environmentally-friendly flame retardants on fire resistance and mechanical properties of rigid polyurethane foams," Polimery 61(2), 113-116. DOI: 10.14314/polimery.2016.113 
Czuprynski, B., Paciorek-Sadowska, J., and Liszkowska, J. (2010). "Properties of rigid polyurethane-polyisocyanurate foams modified with the selected fillers," Journal of Applied Polymer Science 115(4), 2460-2469. DOI: 10.1002/app.30937

Ertaş, M., Fidan, M. S., and Alma, M. H. (2014). "Preparation and characterization of biodegradable rigid polyurethane foams from the liquefied eucalyptus and pine woods," Wood Research 59(1), 97-108.

Esteves, B., Dulyanska, Y., Costa, C., Vicente, J., Domingos, I., Pereira, H., De Lemos, L. T., and Cruz-Lopes, L. (2017). "Cork liquefaction for polyurethane foam production," BioResources 12(2), 2339-2353. DOI: 10.15376/biores.12.2.2339-2353

Fidan, M. S. and Ertaş, M. (2020a). "Optimization of liquefaction parameters of cotton burrs (Gossypium hirsutum L.) for polyurethane-type isolation foams," Kastamonu University Journal of Forestry Faculty 20(1), 15-24.

Fidan, M. S. and Ertaş, M. (2020b). "Biobased rigid polyurethane foam prepared from apricot stone shell based polyol for a thermal insulation application, Part 1:

Synthesis, chemical, and physical properties," BioResources 15(3), 6061-6079. DOI: 10.15376/biores.15.3.6061-6079

Gama, N. V., Soares, B., Freire, C. S. R., Silva, R., Neto, C. P., Barros-Timmons, A., and Ferreira, A. (2015a). "Bio-based polyurethane foams toward applications beyond thermal insulation," Materials \& Design 76, 77-85. DOI:

10.1016/j.matdes.2015.03.032

Gama, N., Soares, B., Freire, C. S. R., Silva, R., Brandão, I., Neto, C. P., BarrosTimmons, A., and Ferreira, A. (2015b). "Rigid polyurethane foams derived from cork liquefied at atmospheric pressure," Polymer International 64(2), 250-257. DOI: $10.1002 /$ pi.4783

Hablot, E., Zheng, D., Bouquey, M., and Avérous, L. (2008). "Polyurethanes based on castor oil: Kinetics, chemical, mechanical and thermal properties," Macromolecular Materials and Engineering 293(11), 922-929. DOI: 10.1002/mame.200800185

Hakim, A. A. A., Nassar, M., Emam, A., and Sultan, M. (2011). "Preparation and characterization of rigid polyurethane foam prepared from sugar-cane bagasse polyol," Material Chemistry and Physics 129(1-2), 301-307. DOI:

10.1016/j.matchemphys.2011.04.008

$\mathrm{Hu}, \mathrm{S}$., and Li, Y. (2014). "Two-step sequential liquefaction of lignocellulosic biomass by crude glycerol for the production of polyols and polyurethane foams," Bioresource Technology 161, 410-415. DOI: 10.1016/j.biortech.2014.03.072

$\mathrm{Hu}$, S., Wan, C., and Li, Y. (2012). "Production and characterization of biopolyols and polyurethane foams from crude glycerol based liquefaction of soybean straw," Bioresource Technology 103(1), 227-233. DOI: 10.1016/j.biortech.2011.09.125

Huang, X. Y., Qi, J. Q., De Hoop, C. F., Xie, J. L., and Chen, Y. Z. (2017a). "Biobased polyurethane foam insulation from microwave liquefaction of woody underbrush," BioResources 12(4), 8160-8179. DOI: 10.15376/biores.12.4.8160-8179

Huang, X., De Hoop, C. F., Xie, J., Hse, C. Y., Qi, J., and Hu, T. (2017b). "Characterization of biobased polyurethane foams employing lignin fractionated from microwave liquefied switchgrass," International Journal of Polymer Science 1, Article ID 4207367. DOI: 10.1155/2017/4207367

Huang, X. Y., De Hoop, C. F., Peng, X. P., Xie, J. L., Qi, J. Q., Jiang, Y. Z., Xiao, H. and Nie, S. X. (2018). "Thermal stability analysis of polyurethane foams made from 
microwave liquefaction bio-polyols with and without solid residue," BioResources 13(2), 3346-3361. DOI: 10.15376/biores.13.2.3346-3361

Janković, B., Manić, N., Dodevski, V., Radović, I., Pijović, M., Katnić, Đ., and Tasić, G. (2019). "Physico-chemical characterization of carbonized apricot kernel shell as precursor for activated carbon preparation in clean technology utilization," Journal of Cleaner Production 236, 117614. DOI: 10.1016/j.jclepro.2019.117614

Kuranska, M., and Prociak, A. (2016). "The influence of rapeseed oil-based polyols on the foaming process of rigid polyurethane foams," Industrial Crops and Products 89, 182-187. DOI: 10.1016/j.indcrop.2016.05.016

Lee, S. H., Teramoto, Y., and Shiraishi, N. (2002). "Biodegradable polyurethane foam from liquefied waste paper and its thermal stability, biodegradability, and genotoxicity," Journal of Applied Polymer Science 83(7), 1482-1489. DOI: 10.1002/app.10039

Lee, S. H., Yoshioka, M., and Shiraishi, N. (2000). "Liquefaction of corn bran (CB) in the presence of alcohols and preparation of polyurethane foam from its liquefied polyol," Journal of Applied Polymer Science 78(2), 319-325. DOI: 10.1002/10974628(20001010)78:2<319::AID-APP120>3.0.CO;2-Z

Levchik, S. V., and Weil, E. D. (2004). "Thermal decomposition, combustion and fireretardancy of polyurethanes-A review of the recent literatüre," Polymer International 53, 1585-1610. DOI: 10.1002/pi.1314

Luo, F., Wu, K., and Lu, M. (2016). "Enhanced thermal stability and flame retardancy of polyurethane foam composites with polybenzoxazine modified ammonium polyphosphates," RSC Advances 6, 13418-13425. DOI: 10.1039/C5RA27256D

Mahmood, N., Yuan, Z., Schmidt, J., Tymchyshyna, M., and Xu, C. (2016). "Hydrolytic liquefaction of hydrolysis lignin for the preparation of bio-based rigid polyurethane foam," Green Chemistry 18, 2385-2398. DOI: 10.1039/C5GC02876K

Modesti, M., Lorenzetti, A., Simioni, F., and Checchin, M. (2001). "Influence of different flame retardants on fire behaviour of modified PIR/PUR polymers," Polymer Degradation and Stability 74(3), 475-479. DOI: 10.1016/S01413910(01)00171-9

Šoštarić, T., Petrović, M., Stojanović, J., Marković, M., Avdalović, J., HosseiniBandegharaei, A., and Lopičić, Z. (2020). "Structural changes of waste biomass induced by alkaline treatment: the effect on crystallinity and thermal properties," Biomass Conversion and Biorefinery. DOI: 10.1007/s13399-020-00766-2

Sung, G., Kim, J. W., and Kim, J. H. (2016). "Fabrication of polyurethane composite foams with magnesium hydroxide filler for improved sound absorption," Journal of Industrial and Engineering Chemistry 44, 99-104. DOI: 10.1016/j.jiec.2016.08.014

Tang, Z., Maroto-Valer, M. M., Andresen, J. M., Miller, J. W., Listemann, M. L., McDaniel, P. L., Morita, D. K., and Furlan, W. R. (2002). "Thermal degradation behavior of rigid polyurethane foams prepared with different fire retardant concentrations and blowing agents," Polymer 43(24), 6471-6479. DOI: 10.1016/S0032-3861(02)00602-X

Tiuc, A. E., Vermeşan, H., Gabor, T., and Vasile, O. (2016). "Improved sound absorption properties of polyurethane foam mixed with textile waste," Energy Procedia 85, 559-565. DOI: 10.1016/j.egypro.2015.12.245 
Vitkauskiene, I., Makuška, R., Stirna, U., and Cabulis, U. (2011). "Thermal properties of polyurethane-polyisocyanurate foams based on poly(ethylene terephthalate) waste," Materials Science 17(3), 249-253. DOI: 10.5755/j01.ms.17.3.588

Xie, J., Qi, J., Hse, C. Y., and Shupe, T. F. (2014). "Effect of lignin derivatives in the bio-polyols from microwave liquefied bamboo on the properties of polyurethane foams," BioResources 9(1), 578-588. DOI: 10.15376/biores.9.1.578-588

Xie, J., Zhai, X., Hse, C. Y., Shupe, T. F., and Pan, H. (2015). "Polyols from microwave liquefied bagasse and its application to rigid polyurethane foam," Materials 8(12), 8496-8509. DOI: $10.3390 / \mathrm{ma} 8125472$

Xue, B. L., Wen, J. L., and Sun, R. C. (2015). "Producing lignin-based polyols through microwave-assisted liquefaction for rigid polyurethane foam production," Materials 8(2), 586-599. DOI: 10.3390/ma8020586

Yan, Y., Pang, H., Yang, X., Zhang, R., and Liao, B. (2008). "Preparation and characterization of water blown polyurethane foams from liquefied cornstalk polyol," Journal of Applied Polymer Science 110(2), 1099-1111. DOI:

10.1002/app.28692

Zhang, G., Wu, Y., Chen, W., Han, D., Lin, X., Xu, G., and Zhang, Q. (2019). “Opencell rigid polyurethane foams from peanut shell-derived polyols prepared under different post-processing conditions," Polymers 11(9), E1392. DOI: 10.3390/polym11091392

Zhang, G., Zhang, Q., Wu, Y., Zhang, H., Cao, J., and Han, D. (2017). "Effect of auxiliary blowing agents on properties of rigid polyurethane foams based on liquefied products from peanut shell," Journal of Applied Polymer Science 134(48), Article ID 45582. DOI: 10.1002/app.45582

Zhang, H., Pang, H., Zhang, L., Chen, X., and Liao, B. (2013). "Biodegradability of polyurethane foam from liquefied wood based polyols," Journal of Polymers and the Environment 21, 329-334. DOI: 10.1007/s10924-012-0542-2

Zhang, Q., Lin, X., Chen, W., Zhang, H., and Han, D. (2020). "Modification of rigid polyurethane foams with the addition of nano- $\mathrm{SiO}_{2}$ or lignocellulosic biomass," Polymers 12(1), E107. DOI: 10.3390/polym12010107

Zhao, Y., Yan, N., and Feng, M. (2012). "Polyurethane foams derived from liquefied mountain pine beetle-infested barks," Journal of Applied Polymer Science 123(5), 2849-2858. DOI: 10.1002/app.34806

Article submitted: March 24, 2020; Peer review completed: May 31, 2020; Revised version received and accepted: June 12, 2020; Published: June 18, 2020.

DOI: 10.15376/biores.15.3.6080-6094 